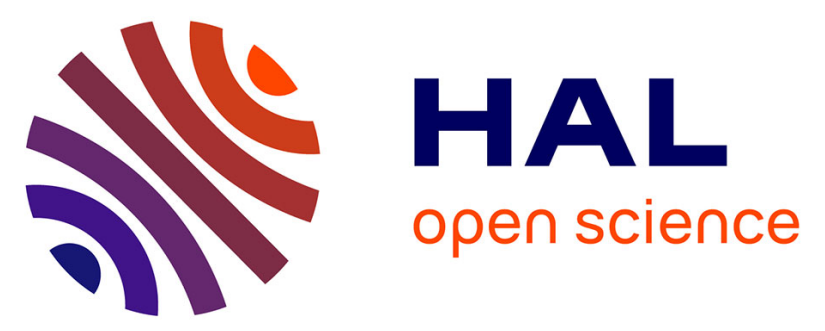

\title{
Vibrational properties of SrCu2O2 studied via Density Functional Theory calculations and compared to Raman and infrared spectroscopy measurements
}

\author{
Jacky Even, Laurent Pedesseau, Olivier Durand, M. Modreanu, G. \\ Huyberechts, Bernard Servet, Odette Chaix-Pluchery
}

\section{To cite this version:}

Jacky Even, Laurent Pedesseau, Olivier Durand, M. Modreanu, G. Huyberechts, et al.. Vibrational properties of $\mathrm{SrCu} 2 \mathrm{O} 2$ studied via Density Functional Theory calculations and compared to Raman and infrared spectroscopy measurements. European Materials Research Society Spring Meeting 2012 (E-MRS Spring 2012), May 2012, Strasbourg, France. pp.113-116, 10.1016/j.tsf.2012.10.130 . hal00805323

\section{HAL Id: hal-00805323 \\ https://hal.science/hal-00805323}

Submitted on 28 Mar 2013

HAL is a multi-disciplinary open access archive for the deposit and dissemination of scientific research documents, whether they are published or not. The documents may come from teaching and research institutions in France or abroad, or from public or private research centers.
L'archive ouverte pluridisciplinaire HAL, est destinée au dépôt et à la diffusion de documents scientifiques de niveau recherche, publiés ou non, émanant des établissements d'enseignement et de recherche français ou étrangers, des laboratoires publics ou privés. 


\section{Vibrational properties of $\mathrm{SrCu}_{2} \mathrm{O}_{2}$ studied via DFT calculations and compared to Raman and infrared spectroscopy}

\section{measurements}

J. Even $^{\text {a)* }}{ }^{\text {, L. Pedesseau }}{ }^{\text {a) }}$, O. Durand ${ }^{\text {a) }}$, M. Modreanu ${ }^{\text {b) }}$, G. Huyberechts ${ }^{\text {c) }}$, B. Servet ${ }^{\text {d) }}$, and O. Chaix-Pluchery ${ }^{\text {e) }}$

a) Université Européenne de Bretagne, INSA, FOTON, UMR CNRS 6082, 20 Avenue des Buttes de Coësmes, F-35708 Rennes, France

b) Tyndall National Institute, Lee Maltings, Prospect Row, Cork, Ireland.

${ }^{c}$ FLAMAC, Technologiepark 903, 9052 Zwijnaarde , Belgium

d) Thales Research \& Technology France, Campus Polytechnique, 1, avenue Augustin Fresnel, 91767 Palaiseau cedex France

e) Laboratoire des Matériaux et du Génie Physique, Grenoble INP - Minatec, 3, parvis Louis Néel, BP 257, 38016 Grenoble Cedex 1, France

\section{Abstract.}

The $\mathrm{SrCu}_{2} \mathrm{O}_{2}$ material is a p-type Transparent Conductive Oxide (TCO). A theoretical study of the $\mathrm{SrCu}_{2} \mathrm{O}_{2}$ crystal is performed with a state of the art implementation of the Density functional theory (DFT). The simulated crystal structure is compared with available X-ray diffraction data and previous theoretical modelling. Density functional perturbation theory (DFPT) is used to study the vibrational properties of the $\mathrm{SrCu}_{2} \mathrm{O}_{2}$ crystal. A symmetry analysis of the optical phonon eigenvectors at the Brillouin zone center is proposed. The Raman spectra simulated using the derivatives of the dielectric susceptibility, show a good agreement with Raman scattering experimental results.

Keywords: DFT, $\mathrm{SrCu}_{2} \mathrm{O}_{2}$, X-ray scattering, Raman spectroscopy.

* Corresponding author. E-mail address: jacky.even@insa.rennes.fr 


\section{Introduction}

$\mathrm{SrCu}_{2} \mathrm{O}_{2}$ is a p-type transparent conductive oxide (TCO) [1-3] which is combining high electrical conductivity and optical transparency, like in n-type TCO. TCO materials are used for electrostatic shielding, antistatic screens, transparent heating devices, solar cells and even organic light emitting diodes [3, 4]. The vibrational properties of $\mathrm{SrCu}_{2} \mathrm{O}_{2}$ crystal are only reported in a few experimental papers, but vibrational spectroscopy could offer a very interesting alternative for material characterisation [5]. Most theoretical studies focus indeed on the electronic properties, band structures or acceptor defects [5-11]. The origin of the transparency was also investigated systematically in related compounds $\mathrm{A}^{\mathrm{II}} \mathrm{Cu}_{2} \mathrm{O}_{2}$ where $\mathrm{A}^{\mathrm{II}}=\mathrm{Mg}, \mathrm{Pb}, \mathrm{Ca}, \mathrm{Ba}, \mathrm{Sr}$.

In this paper, a theoretical study of the $\mathrm{SrCu}_{2} \mathrm{O}_{2}$ crystal is performed with a state of the art implementation of the Density functional theory (DFT). The simulated crystal structure is in reasonable agreement with available X-ray diffraction data. Density functional perturbation theory (DFPT) is used to study the vibrational properties of the $\mathrm{SrCu}_{2} \mathrm{O}_{2}$ crystal. A symmetry analysis of the optical phonon eigenvectors at the Brillouin zone center is proposed. Born charge tensors are determined for each atom. The Raman spectra simulated using the derivatives of the dielectric susceptibility, is compared with Raman scattering experimental results.

\section{Experimental and computational details}

Ceramics of $\mathrm{SrCu}_{2} \mathrm{O}_{2}$ were synthesized by reacting a stoichiometric mixture of $\mathrm{Cu}_{2} \mathrm{O}(99.5 \%)$ and $\mathrm{Sr}(\mathrm{OH})_{2} .8 \mathrm{H}_{2} \mathrm{O}$ for $40 \mathrm{~h}$ in a nitrogen flow at $950{ }^{\circ} \mathrm{C}$. The reaction product was ground and hot pressed into a pellet by at $975^{\circ} \mathrm{C}$. 
The room temperature Raman measurements have been performed in a backscattering geometry using a Jobin Yvon /Horiba LabRam spectrometer equipped with a $\mathrm{N}_{2}$-cooled CCD detector, and the $488 \mathrm{~nm} \mathrm{Ar}^{+}$laser line as excitation.

The theoretical study of $\mathrm{SrCu}_{2} \mathrm{O}_{2}$ is performed using the Density Functional Theory (DFT) implementation available in the ABINIT package [12]. A local density approximation (LDA) is used for the exchange-correlation functional [13]. Norm-conserving pseudopotentials are constructed for $\mathrm{Sr}\left[4 \mathrm{~s}^{2} 4 \mathrm{~s}^{6} 5 \mathrm{~s}^{2}\right], \mathrm{Cu}\left[3 \mathrm{~d}^{10} 4 \mathrm{~s}^{1}\right]$ and $\mathrm{O}\left[2 \mathrm{~s}^{2} 2 \mathrm{p}^{4}\right]$ atoms in a standard format [14] using the OPIUM code [15]. These valence configurations are similar to the ones used in previous DFT simulations of the ground state [5-11] and give a good description of the conduction band and valence band edges close to the band gap [5-11]. A plane-wave basis set with an energy cut-off of $950 \mathrm{eV}$ is used to expand the electronic wavefunctions. The reciprocal space integration is performed over a $12 \times 12 \times 12$ Monkhorst-Pack grid [16]. Energy convergence is accurately reached with tolerance on the residual potential which stems from difference between the input and output potentials. The crystal structure has been relaxed until the forces acting on each atom are smaller than $5.10^{-5} \mathrm{eV} / \AA$.

The so-called $2 n+1$ theorem [17] within the DFPT provides a direct access to the second and third-order response function and has been used for the vibrational analysis of various materials [18-20]. A DFPT implementation is available in the ABINIT package [12] but a LDA must be used for the exchange-correlation functional in the ground state computation.

\section{Results and discussion}

3.1 Vibrational modes at $\Gamma$ point

\subsubsection{Symmetry analysis}


$\mathrm{SrCu}_{2} \mathrm{O}_{2}$ exhibits a tetragonal structure (space group $\mathrm{I}_{1} /$ amd or $\mathrm{D}_{4 \mathrm{~h}}^{19}$ ) with two formula units per unit cell. In this crystal structure, the $\mathrm{Sr}$ atoms are at the center of a distorted octahedron formed by $\mathrm{O}$ atoms. The ten atoms of the primitive cell give rise to 30 zone center vibrational modes. The $\mathrm{Sr}, \mathrm{Cu}$ and $\mathrm{O}$ atoms are in special Wyckoff positions $4 \mathrm{a}, 8 \mathrm{~d}$ and $8 \mathrm{e}$ with site symmetry $D_{2 d}$ (or $\left.-42 \mathrm{~m}\right), C_{2 h}$ (or $\left.2 / \mathrm{m}\right)$ and $C_{2 v}$ (or $\left.\mathrm{mm}\right)$, respectively. From the correlation method [21], we can identify the species of the site group for each lattice vibration and correlate these species with the $\mathrm{D}_{4 \mathrm{~h}}$ factor group species.

The irreducible representations relative to the lattice vibrations involving the $\mathrm{Sr}$ atoms are

$$
\Gamma_{\mathrm{Sr}}=\mathrm{A}_{2 \mathrm{u}}+\mathrm{B}_{1 \mathrm{~g}}+\mathrm{E}_{\mathrm{u}}+\mathrm{E}_{\mathrm{g}},
$$

those involving the $\mathrm{Cu}$ atoms are

$$
\Gamma_{\mathrm{Cu}}=\mathrm{A}_{1 \mathrm{u}}+2 \mathrm{~A}_{2 \mathrm{u}}+\mathrm{B}_{1 \mathrm{u}}+2 \mathrm{~B}_{2 \mathrm{u}}+3 \mathrm{E}_{\mathrm{u}},
$$

and those involving the $\mathrm{O}$ atoms are

$$
\Gamma_{\mathrm{O}}=\mathrm{A}_{1 \mathrm{~g}}+\mathrm{A}_{2 \mathrm{u}}+\mathrm{B}_{1 \mathrm{~g}}+\mathrm{B}_{2 \mathrm{u}}+2 \mathrm{E}_{\mathrm{u}}+2 \mathrm{E}_{\mathrm{g}}
$$

After subtraction of the three acoustic modes $\left(\mathrm{A}_{2 u}+\mathrm{E}_{u}\right)$ of the total representation of the crystal, the irreducible representations associated with the vibrational modes are

$$
\Gamma=A_{1 g}+A_{1 u}+3 A_{2 u}+2 B_{1 g}+B_{1 u}+3 B_{2 u}+5 E_{u}+3 E_{g},
$$

where $A_{1 g}, B_{1 g}$ and $E_{g}$ are Raman-active modes, $A_{2 u}$ and $E_{u}$ are IR-active modes, the other modes being silent. Thus, six Raman lines and eight IR lines are expected in the spectra. Concerning the IR spectra, it should be noted that the $A_{2 u}$ modes involve atom displacements parallel to the $\mathrm{z}$ axis whereas in $E_{u}$ modes, they are perpendicular to the $\mathrm{z}$ axis. As for the Raman modes, the $A_{l g}$ mode involves only $\mathrm{O}$ atom displacements and the $\mathrm{Cu}$ atoms are motionless.

\subsubsection{Dielectric tensors}


The $\mathrm{Z}_{\mathrm{ij}}$ Born charge tensors for each atom have been calculated via DFPT in the $\mathrm{SrCu}_{2} \mathrm{O}_{2}$ crystal lattice. These tensors reflect the sites symmetries and form the basis of the computation of the dielectric constants and dynamical matrix. Table I shows the results for the

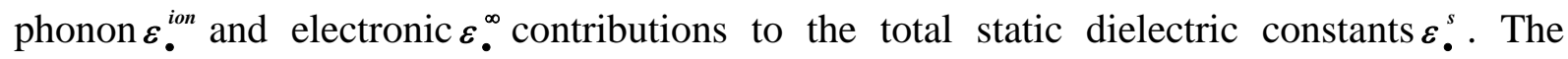
phonon contribution to the static dielectric constant is large, especially along the $\mathrm{z}$ axis. The anisotropy of the static dielectric constant is then mostly related to this contribution.

\subsubsection{Comparison to Infrared spectroscopy for polar modes}

A previous experimental study by infrared spectroscopy [5] has shown peaks located either in the far-infrared spectral range at 123,147 and $251 \mathrm{~cm}^{-1}$ or in the mid-infrared spectral range, with a strong peak at $578 \mathrm{~cm}^{-1}$ and a shoulder at about $600 \mathrm{~cm}^{-1}$. This observation is compared to the theoretical calculation.

Our DFPT calculations provide peaks located at $39.0 \mathrm{~cm}^{-1}\left(\mathrm{E}_{\mathrm{u}}\right), 106.9 \mathrm{~cm}^{-1}\left(\mathrm{E}_{\mathrm{u}}\right), 124.6$ $\mathrm{cm}^{-1}\left(\mathrm{~A}_{2 \mathrm{u}}\right), 135.0 \mathrm{~cm}^{-1}\left(\mathrm{E}_{\mathrm{u}}\right), 225.8 \mathrm{~cm}^{-1}\left(\mathrm{~A}_{2 \mathrm{u}}\right), 248.0 \mathrm{~cm}^{-1}\left(\mathrm{E}_{\mathrm{u}}\right), 608.2 \mathrm{~cm}^{-1}\left(\mathrm{E}_{\mathrm{u}}\right)$, and $626.5 \mathrm{~cm}^{-1}$ $\left(A_{2 u}\right)$. In fact, this calculation reveals two new modes which are not observed yet at $39.0 \mathrm{~cm}^{-1}$ and probably the one at $106.7 \mathrm{~cm}^{-1}$. The high frequency modes observed at $578 \mathrm{~cm}^{-1}$ and 600 $\mathrm{cm}^{-1}$ might be assigned to the computed $\mathrm{E}_{\mathrm{u}}\left(608.2 \mathrm{~cm}^{-1}\right)$ and $\mathrm{A}_{2 \mathrm{u}}\left(626.5 \mathrm{~cm}^{-1}\right)$ ones, but extensive studies by infrared spectroscopy should be performed, particularly using light polarization in order to get a precise mode assignment. We also note that there is a tendency to overestimate the frequencies of the modes, both for polar and unpolar modes (see section $3.2 .1)$

3.2 Comparison to Raman scattering experiments for unpolar modes

\subsubsection{Experimental results}

In a previous study, microRaman mapping of a bulk polycrystalline $\mathrm{SrCu}_{2} \mathrm{O}_{2}$ target has already revealed features located at 188, 236, 286 and $530 \mathrm{~cm}^{-1}$ assigned to Raman active modes for the tetragonal phase of $\mathrm{SrCu}_{2} \mathrm{O}_{2}$ [5]. A new study of a carefully polished $\mathrm{SrCu}_{2} \mathrm{O}_{2}$ 
sample (figure 1) shows features located at 112, 133, 156, 183, 230, 286, 455, 497, 524, 584 and $687 \mathrm{~cm}^{-1}$. The peaks at 183,230, 286 and $524 \mathrm{~cm}^{-1}$ correspond to the results quoted in the previous study. The shoulder observed at $497 \mathrm{~cm}^{-1}$ was also present in the spectrum shown in ref. [5]. A spectrum of a $\mathrm{Cu}_{2} \mathrm{O}$ powder obtained under the same experimental conditions sample shows (figure 1) features located at 114, 126, 150, 179, 191, 200, 220, 288, 332, 412, 480 and $620 \mathrm{~cm}^{-1}$.

Indeed, our DFPT calculations provide the Raman peaks located at $124.5 \mathrm{~cm}^{-1}\left(\mathrm{E}_{\mathrm{g}}\right)$, $154.7 \mathrm{~cm}^{-1}\left(\mathrm{E}_{\mathrm{g}}\right), 186.2 \mathrm{~cm}^{-1}\left(\mathrm{~B}_{1 \mathrm{~g}}\right), 513.9 \mathrm{~cm}^{-1}\left(\mathrm{E}_{\mathrm{g}}\right), 557.1 \mathrm{~cm}^{-1}\left(\mathrm{~B}_{1 \mathrm{~g}}\right)$, and $558.2 \mathrm{~cm}^{-1}\left(\mathrm{~A}_{1 \mathrm{~g}}\right)$. So, we do not get any mode within the interval from 200 to $480 \mathrm{~cm}^{-1}$ which is definitively belonging to the $\mathrm{CuO}_{2}$ crystal. X-ray diffraction (not shown here) has confirmed the presence of a $\mathrm{Cu}_{2} \mathrm{O}$ polycristalline extra-phase in the $\mathrm{SrCu}_{2} \mathrm{O}_{2}$ pellet studied in the present paper. Such an additional phase was not present in the following study reported in ref [5], and may be due to a slight variation of the elaboration conditions.

We may then conclude that the shoulder located at $497 \mathrm{~cm}^{-1}$ and the strong peak 524 $\mathrm{cm}^{-1}$ (figure 1) can be attributed to the polycrystalline $\mathrm{SrCu}_{2} \mathrm{O}_{2}$ sample. In the low frequency range (below $230 \mathrm{~cm}^{-1}$ ), the vibrational modes of $\mathrm{SrCu}_{2} \mathrm{O}_{2}$ are mixed with vibrational modes attributed to a residual $\mathrm{Cu}_{2} \mathrm{O}$ powder used for the synthesis of the materials. Concerning the two modes at 236 and $286 \mathrm{~cm}^{-1}$ previously attributed to the $\mathrm{SrCu}_{2} \mathrm{O}_{2}$ lattice, they are very similar to those observed in $\mathrm{Cu}_{2} \mathrm{O}$ and are probably oxygen-related vibration modes identical in both crystal structures.

Figure 2 is schematic illustrations of the eigenvectors associated to Raman active optical mode calculated at frequencies equal to $558.2 \mathrm{~cm}^{-1}\left(\mathrm{~A}_{1 \mathrm{~g}}\right)$. The $\mathrm{Cu}$ atoms are not represented. Only four slices at $\mathrm{z}=0,1 / 4,1 / 2$, and $3 / 4$ are needed to correctly represent the crystal as defined in ref. [1]. For the $\mathrm{A}_{1 \mathrm{~g}}$ mode (figure 2), $\mathrm{O}$ atoms vibrate only along the $\mathrm{z}$ 
axis. Some $\mathrm{O}$ atoms vibrate in phase opposition with other $\mathrm{O}$ atoms located in the same crystalline layer.

\subsubsection{Simulation of Raman spectra}

The Raman susceptibility $\alpha^{v}$ tensors for a given vibrational eigenmode $v$ have been calculated following standard definitions $[12,22,23]$ :

$$
\alpha_{\mathrm{ij}}^{\mathrm{v}}=\left.\sqrt{\Omega} \sum_{\mathrm{n}} \sum_{1} \frac{\partial \chi_{\mathrm{ij}}}{\partial \mathrm{r}_{1}}\right|_{\mathrm{n}} \frac{\xi_{\mathrm{nl}}^{\mathrm{v}}}{\sqrt{\mathrm{m}_{\mathrm{n}}}},\left\{\begin{array}{l}
\mathrm{n} \equiv \mathrm{Sr}, \mathrm{Cu}, \mathrm{O} \\
\mathrm{i}, \mathrm{j}, 1 \equiv \mathrm{x}, \mathrm{y}, \mathrm{z}
\end{array}\right.
$$

where $\Omega$ is the volume of the primitive cell, $\chi_{i j}$ is the dielectric susceptibility tensor, $\mathrm{r}_{1}$ is the displacement of $\mathrm{n}$ along the Cartesian axes, $\mathrm{m}_{\mathrm{n}}$ is the mass of $\mathrm{n}$, and $\xi_{n l}^{v}$ the normalized eigenmode of the atom $\mathrm{n}$ in the vibrational mode $v$.The calculation of the Raman susceptibility requires knowledge of the derivatives of the dielectric polarization tensor which is the more demanding computational part. The three derivatives (Table III) of the dielectric polarization tensors of $\mathrm{Cu}$ atom are equal to zero (see section 4.2.1). The Raman susceptibility tensors were computed for light polarizations parallel $(\mathrm{V})$ and orthogonal $(\mathrm{H})$ to the incident one. HH and HV Raman spectra were then calculated considering polycrystalline samples (figure 3). The spectra are shown over the entire $\left[0-700 \mathrm{~cm}^{-1}\right]$ energy range on the left part of the figure. Three peaks are located at low energy whereas the three others are close to each others, two of them being almost degenerated ( $A_{1 g}$ and $B_{1 g}$ modes). The right part of figure 3 shows that the $A_{1 g}$ mode is very sensitive to polarizations contrary to the other one. $\mathrm{A}$ tentative interpretation of the experimental results (figure 1) can be proposed. The shoulder located at $497 \mathrm{~cm}^{-1}$ could be attributed to the high frequency $E_{\mathrm{g}}$ mode $\left(513.9 \mathrm{~cm}^{-1}\right)$ whereas the strong peak at $524 \mathrm{~cm}^{-1}$ could correspond to the sum of the almost degenerated high frequency $\mathrm{A}_{1 \mathrm{~g}}\left(558.2 \mathrm{~cm}^{-1}\right)$ and $\mathrm{B}_{1 \mathrm{~g}}\left(557.1 \mathrm{~cm}^{-1}\right)$ modes. A better agreement between computed and experimental frequencies may be obtained by refining the DFPT computation, 
either by using an improved exchange-correlation functional or by taking into account core electrons into the electronic configurations for the atoms. More, a better agreement could be expected taking into account temperature induced shifts of vibrational frequencies. Theoretical frequencies are indeed computed by DFT at $\mathrm{T}=0 \mathrm{~K}$, whereas experiments are only available up to now at room temperature.

\section{Conclusion}

In summary, this paper presented a theoretical analysis of the mechanical structure, and vibrational properties of $\mathrm{SrCu}_{2} \mathrm{O}_{2}$ crystal lattice. A first DFPT computation of the dynamical matrix at the Brillouin zone center is proposed. The Born charges and the dielectric tensors are calculated and the Raman scattering spectra is simulated. Additional Raman measurements of $\mathrm{SrCu}_{2} \mathrm{O}_{2}$ and $\mathrm{Cu}_{2} \mathrm{O}$ samples are performed. A tentative assignment of nonpolar vibrational high frequency modes is proposed for $\mathrm{SrCu}_{2} \mathrm{O}_{2}$.

\section{Acknowledgments}

The ab initio simulations have been performed on HPC resources of CINES and IDRIS under the allocation 2012-[x2012096724] made by GENCI (Grand Equipement National de Calcul Intensif). 
[1] Von Chr. L. Teske, H. K. Mueller-Buschbaum, Z. Anorg. Allg. Chem. 379 (1970) 113

[2] R. O. Suzuki, P. Bohac, L.J. Gauckler, J. Am. Ceram. Soc. 75 (1992) 2833

[3] H. Kawazoe, M. Yasukawa, H. Hyodo, M. Kurita, H. Yanagi, H. Hosono, Nature (London) 389 (1997) 939

[4] J.F. Wagner, Science (2003) 1245

[5] M. Modreanu, M. Nolan, S.D. Elliott, O. Durand, B. Servet, G. Garry, H. Gehan, G. Huyberechts, E.L. Papadopoulou, M. Androulidaki, E. Aperathitis, Thin Solid Films 515 (2007) 8624

[6] H. Ohta, M. Orita, M. Hirano, I. Yagi, K. Ueda and H. Hosono, J. Appl. Phys., 91 (2002) 3074

[7] X. Nie , S. H. Wei and S. B. Zhang, Phys. Rev. B, 65 (2002) 075111

[8] J.P. Hu, D.J. Payne, R.G. Egdell, N.M. Harrison, V.R. Dhanak, Chem. Phys. Lett., 450 (2007) 39

[9] K. G. Godinho, G. W. Watson, A. J. H. Green, D. J. Payne, J. Harmer and R. G. Egdell, J. Mater. Chem., 18 (2008) 2798

[10] M. Nolan, Thin Solid Films 516 (2009) 8130

[11] K. G. Godinho, J. J. Carey, B. J. Morgan, D. O. Scanlon and G. W. Watson, J. Mater. Chem., 20 (2010) 1086

[12] X. Gonze, B. Amadon, P. M. Anglade, J.M. Beuken, F. Bottin, P. Boulanger, F. Bruneval, D. Caliste, R. Caracas, M. Cote, T. Deutsch, L. Genovese, Ph. Ghosez, M. Giantomassi, S. Goedecker, D.R. Hamann, P. Hermet, F. Jollet, G. Jomard, S. Leroux, M. Mancini, S. Mazevet, M.J.T. Oliveira, G. Onida, Y. Pouillon, T. Rangel, G.M. Rignanese, D. Sangalli, R. Shaltaf, M. Torrent, M.J. Verstraete, G. Zerah, J.W. Zwanziger, Computer Phys. Commun. 180 (2009) 2582

[13] J. P. Perdew and Y. Wang, Phys. Rev. B, 45 (1992) 13244 
[14] M. Fuchs and M. Scheffler, Comp. Phys. Comm., 119, (1999) 67

[15] I. Grinberg, N. Ramer, and A. Rappe, Phys. Rev. B, 62 (2000) 2311

[16] J. D. Pack and H. J. Monkhorst, Phys. Rev. B, 16 (1977) 1748.

[17] X. Gonze and J. P. Vigneron, Phys. Rev. B, 39 (1989) 13120

[18] P. Giannozzi, S. de Gironcoli, P. Pavone, and S. Baroni, Phys. Rev. B, 43 (1991) 7231

[19] X. Gonze and C. Lee, Phys. Rev. B, 55 (1997) 10355

[20] S. Baroni, S. de Gironcoli, A. Dal Corso, and P. Giannozzi, Rev. Mod. Phys., 73 (2001) 515

[21] W.G. Fateley, N.T. McDevitt and F.F. Bentley, Appl. Spectrosc. 25 (1971) 155]

[22] M. Cardona and G. Güntherodt, "Light scattering in solids II: basic concepts and instrumentations", (Springer-Verlag Berlin and Heidelberg GmbH \& Co.K, 1982)

[23] R. Loudon, Advances in Physics 13 (1964) 423-482 
Figure captions:

Figure 1: Experimental Raman spectra of $\mathrm{Cu}_{2} \mathrm{O}$ powder and polycrystalline $\mathrm{SrCu}_{2} \mathrm{O}_{2}$ at room temperature.

Figure 2: Representation of the $\mathrm{SrCu}_{2} \mathrm{O}_{2} \mathrm{~A}_{1 \mathrm{~g}}$ normal mode at $\mathrm{z}=0,1 / 4,1 / 2$, and 3/4.

Figure 3: DFT HH and HV Raman spectra of $\mathrm{SrCu}_{2} \mathrm{O}_{2}$ 